\title{
Environmental Journalism as a Management Tool for Poverty Reduction: Considerations on Albanian Current Developments
}

\author{
Elda Zotaj \\ Lecturer in Law and Management, "Luarasi" University, Faculty of Law, Tirana Albania \\ Email:elda_zotaj@hotmail.com \\ Luljeta Buza \\ Professor Associate, "Luarasi" University, Faculty of Law, Tirana. Albania \\ Email: luljetabuza@yahoo.com
}

\section{Doi:10.5901/mjss.2014.v5n23p187}

\begin{abstract}
The paper is conceived on an empirical study explaining the relationship between different actors dealing with environmental and poverty reduction issues, such as journalists, NGOs as well as educational institutions, aiming to raise the public awareness and participation while proposing concrete policies for improvement. Interviews and surveys have been conducted to better understand if the link between the environmental communicators and the civil society is actually at the level of efficiency it should to bring the significant change they are expected to. As current developments stress the linking environmental concerns with poverty reduction measures for sustainability, the study answers questions on the level of knowledge and training journalists gain since during their higher education as well as through common environmental focused activities with local environmental NGOs. Conclusions raise problems about lack of proper specialization of journalists, and the need for a better cooperation between different stakeholders in order to achieve sustainability and concrete results.
\end{abstract}

Keywords: Environment, Journalism, Poverty Reduction, NGOs, Management

\section{Introduction}

In these last years, 2005 - 2014, "EU Integration" has become Albania's key foreign policy priority and is having, and will continue to have a significant influence on the preparation of local strategies, including environmental and sustainability policies.(National Environmental Strategy 2008). Albania has undergone a transformation from a centrally planned economy to a market economy through painful and difficult economic transformations, including environmental issues.

Like most other developing countries, during this transition period the environmental problems affected the quality of lives of Albanian people. Many of these problems have resulted due to a lack of understanding and concern about environmental and sustainable development issues which led to over-exploitation of natural resources and badly planned development and industrial projects, which added to the population internal migration helped increase of socio-economic problems and large scale air, water and soil pollution. The achievement of a balance between economic development and nature preservation was established after the fall of the social order during the last decades. The history of such developments was considered as a positive process, because the approach to sustainable environmental development could be initially taken during the process of structural transformations.

This new development of the social structure meant new actors operating in a certain environmental area, since there was an increase of number of civil society organizations that were established aiming to play a role in the decision making and policy implementation in the national area. Having this mission national and international agencies, governments, and foundations worked and are still working together to build their administrative, technical and strategic capacities.

In general, most of the efforts of environmental NGOs in promoting environmental management are often linked with community development and poverty reduction strategies and trainings. In order to ensure people make positive choices about the environmental impacts of their lifestyles, there is an urgent need to raise public awareness on environmental and development issues. It is worth to mention the fact that public awareness began to highlight the ecological orientation at the beginning of the reorganization, when ecological problems become one of the first issues in the mass media. The journalists' education and training deserve a special attention since their role and impact on such 
issues is very decisive; despite that they still have to deal with everyday challenges of fewer jobs, editorial disinterest, and a public that despite of its recently raised interest in climate change remains mostly apathetic.

The study highlights the necessity of developing the Environmental Journalism, to cover complex and controversial environmental stories ranging from indoor and outdoor air quality to sprawl and bioterrorism. (Bernadette, West \& Greenburg, 2005). Since the journalists enforce civil society and provide help to the development of the quality of life of citizens, it is highlighted the importance of developing new strategies in covering the environmental issues since the Albanian media usually is focused on "ecological" topics only in isolated cases and often in a deliberately controversial way, even though the tendency that the interest for environmental news will increase seems optimistic.

\section{Literature Overview - Theoretical Framework}

"We generate our own environment. We get exactly what we deserve. How can we resent a life we've created ourselves? Who's to blame, who's to credit but us? Who can change it, anytime we wish, but us?" (W. Clement Stone. 2014).

Taken together, all of these human traits -intellectual, communicative, and social- have not only emerged from natural evolution and are inherently human; they can also be placed at the service of natural evolution to consciously increase biotic diversity, diminish suffering, foster the further evolution of new and ecologically valuable life-forms, and reduce the impact of disastrous accidents or the harsh effects of mere change. (Mass-media-and-our-environment, 2014).

In general, ecological modernization theory argues that in the course of environmental transformation processes, environmental NGOs will shift from protest and confrontation to more cooperative stances toward government and industry, encouraging environment-oriented business practices.

"Different scholars have written that intercultural competence does not comprise individual traits but is rather the characteristic of the association between individuals and that no prescriptive set of characteristics guarantees competence in all intercultural situations" (Lustig, W. Myron., \& Koester, Jolene (2003). This kind of comparative analysis has the potential, as Byram (1997) notes, to turn "learners' attention back on the practices, beliefs and social identities". The media and NGOs must strive to create experiences that challenge our publics' perspectives both locally and globally.

"Schools need to work toward environmental sustainability by becoming greener, reducing school and personal carbon footprints, promoting a commitment to lifelong environmental responsibility, and incorporating environmental education into the curriculum"(National Association of Industrial Technology-NAIT, 2010). "School should play a crucial role as an informative institution and in creating appropriate attitude toward the environment among students" (Knapp \& Poff 2001). However, as a previous study conducted through law and political sciences students in Albania shows, "a considerably low level of environmental knowledge among all the investigated students and revealed that public suffers from an environmental literacy gap that of course appears to be decreasing. Only $14 \%$ of all students identified correct answers for the six questions included in the "knowledge indicator"; $67 \%$ was able to respond correctly to three questions." (Buza, 2010)

As intermediary organizations, NGOs can play a pivotal role in improving both environmental and competitive performances of Small and Medium-sized Enterprises (SMES) ${ }^{1}$. They can support SMEs with 'green' (micro-) credits, technical support, and employee training; they can facilitate links with business partners, government, and development agencies; and they can promote institutional conditions under which SMEs can improve both environmental performance and competitiveness (Gombault \& Versteege, 1999; Frijns \& Van Vliet, 1999; Bianchi \& Noci, 1998; Korten, 1987).

"...poverty reduction and environmental conservation are not opposing goals and that they are, in fact, totally dependent on each other. In other words, investing in sound environmental management is essential for successful longterm poverty reduction and conversely, environmental goals cannot be achieved without parallel development gains." (Halverson \& McNeill, 2008)

\section{Methodology of the Study}

Participants: A considerable number of different social groups from Tirana, the capital city of Albania, became part of the research. The target people were 200 people selected at random, 50 student of journalism and 15 journalists

${ }^{1}$ According to definitions of SME on the Web, SMEs are companies whose headcount or turnover falls below certain limits. The abbreviation SME occurs commonly in the EU and in international organizations, such as the World Bank, the United Nations and the WTO, but less so in the US. 
representing both electronic and printed media. They were questioned about their attitudes and their experiences.

Instruments: Interviews were undertaken with the students of journalism in the frame of a broader activity increasing public awareness of the environment problems in Tirana. A group discussion was arranged providing the opportunity for each group to summarize their opinions and then provide their concerns and their statements.

A questionnaire was administered in March 2014 and was based on the strategic plan of the central government and consisted of four questions: 1 .Which is the role of media regarding the protection of the environment? 2 . What about the quality of environmental journalists and poverty reduction programs? 3. Does the relationship between media, NGOs and governmental institutions work at a proper level? 4. Do the journalism faculty students feel ready to cope with environmental events at a satisfactory and confident attitude gained through current higher education curricula? The results of this study are presented as follows according to the questions.

\section{Findings and Discussion}

Civil sector dealing with environment issues operating in Albania grew bigger during the last years, aiming to implement activities and to educate the population have a better attitude on the environment. When asking Albanian NGOs ' representatives about the main accomplishments in achieving good results, $92 \%$ of them listed as first, the enforcement of environmental legislative instruments, second the media coverage, and last but not least communication between the lobby groups and the implementation of environmental programs (on regional or local level). $97 \%$ of them highlighted as very important the role of participation of the public into the decision-making process.

One question was directed at relevant representatives of stakeholders groups asking them about the main constraints that they encountered in implementing sustainable development objectives in the area they operate. 90\% of them highlighted the lack of financial resources and capacities. $87 \%$ of them listed the lack of information or public awareness and the unfavorable economic situation as the main reason of the difficulties the NGOs are confronting with. Other serious constraints that have appeared in their answers were 95\% because of low political support, $84 \%$ of low public participation, $85 \%$ the lack of media support, and $72 \%$ of low attention of central and local government.

One of the most effective ways of getting the message across to the largest possible audience in the whole country is through mass media, including television told $98 \%$ of the interviewers. $90 \%$ of them considered media as the potential of being extremely effective instrument for environmental communication, but $75 \%$ of them pointed out that media has not been sufficiently enough exploited for this purpose.

Television and Internet are considered as excellent opportunities to reach out all people throughout Albania. The big project of the government named "Albania in the New Digital Area" is considered by $97 \%$ as a project which will have a direct impact even in the protection of the environment. As the electronic media attracts audiences ranging from the educated elite to poor villagers in all parts of the county it is considered by $100 \%$ of the environmental Albanian NGOs as an imperative need to use it, for raising their capacities and promoting environmental awareness campaigns.

There are a great number of good programs on TV but very few articles in the written press that treat environmental issues told $86 \%$ of the students of journalism, and $75 \%$ of them think that through printed media and TV they can raise their knowledge and their responsibility for environment protection. $86 \%$ of them consider environmental documentaries shown on TV as too much academic in the way how they treat and present environmental issues. $86 \%$ of them consider NGOs as good partners to increase the awareness among rural and urban populations on environmental issues. $75 \%$ of the interviewers considered themselves to be active in environmental issues.

\section{What is Environmental Journalism}

The importance of the media today is immense. "Numerous politicians have seized absolute power and muzzled the press; never in history has the press seized absolute power and muzzled the politicians. (Bismarck)². Never before in Albanian history has the media had such a significant impact on our lives and behavior, for $96 \%$ of the interviewers the mass media is a significant force which reflects and creates the culture and nothing can be done without it today. As the media is considered to be the fourth power, after the Executive, Legislative and the Judiciary, everybody should know what Environmental Journalism is.

Do media play a role in the protection of the environment? At what level is the cooperation between media and different stakeholders? Answering these questions adequately necessitates a conceptual definition of environmental

${ }^{2}$ Bismarck, Karl von Schonhausen, Born on February 16, 1961 in Zürich. German statesman of the Christian Democratic Union of Germany. Wikipedia. 
journalism which within the scope of environmental communication points out that its roots can be traced by the nature of writing. The use of this information can help the two parties as well as educational institutions to achieve better results from the activities which are considered as more effective in imparting environmental knowledge and motivating them to action. As the field of environmental journalism covers a wide variety of topics so as to advance public understanding on environmental issues on improving the quality, accuracy, and visibility of environmental reporting, $90 \%$ of the interviewers considered environment as an integrated subject.

$85 \%$ of journalists perceive water concerns as the most important environmental issue, followed by atmospheric air pollution concerns, and waste management issues; $85 \%$ of them prefer to deal with and more likely to prioritize specific, local environmental issues than global environmental concerns, while "environmental concern is a global concern only for local and central government because of the EU directives" told 78\% of NGOs.

Trying to convince people about the importance of protecting the environment sometimes falls on deaf ears. Quite a considerable number of people are simply not interested; society tends to assume that things like land, water resources, plants, animals, and trees - the resources they depend on for their livelihoods - will always be there. Catching audiences' and readers' attention is not the only hard thing environmental journalists have to face. Writing about the environment as a core issue for society sets numerous challenges for journalists. $100 \%$ of interviewers consider media as one of the most decisive factors in the protection of the environment. The use of maximum positive elements of what television can offer may be illustrated with the assistance offered by the public after the winter floods in the Northern part of Albania in sign of national and international solidarity to help the victims of natural disaster. According to them if the event is presented at the right moment, the article, interview, or video will then have the maximum effect; it will be "news", and the media thrive on "news" thought $90 \%$ of the interviewers. $90 \%$ of them consider as very important in order to be a good environmental journalist, a deep understanding theory and practice, a special accuracy to language and terminology, detailed information on past environmental issues, current developments of legislation as well as communication skills to transmit a clear message and explanation of the phenomenon. The use of this information can help them and educational institutions achieve better results from the activities which are considered as more effective in imparting environmental knowledge and motivating them to action. (L.Buza Problems of Education in the 21st Century. 2010). The recognition of these challenges and a solution to them will impact the protection of environment and the creation of a collective dialogue with the civil society.

Environmental and scientific training as well as limited access to official governmental data on environmental conservation are core deficiencies that the environmental journalism is lacking. Reporters without specialized training might ignore complicated environmental stories altogether or, if they attempt them, the results might be less than satisfactory for readers. The continual training influences the improvement of the media's presentation of environmental issues putting at stake public perceptions. In recent years, it seems as though media interest in the environment has taken a backseat to other issues impacting the international scenario.

\section{Albanian Environmental NGOs}

More recently, the Internet has increased its role throughout the country and it throws more light on actual and potential role of NGOs in this changing societal context. This study will highlight the theories of ecological modernization and network society.

Non-governmental organizations are becoming increasingly visible players in Albania`s environmental politics. To gain a better understanding of developmental trends and engagement in governance processes, the study was conducted on the environmental NGOs in Albania. The results suggest that two clusters of organizations have emerged. The first group consists of small organizations which were highly professional and the second cluster of international organizations that engage in policymaking in the international and national areas, which tend to sponsor activities and take action on behalf of their members and provide environmental and governmental support services at the local level. Although the former cluster is comprised of well-capacitated organizations, NGOs in latter group often are overlooked by agencies, governments and foundations, even though they make important contributions to environmental governance. Although a watchdog outside the government was clearly needed, sometimes the environmental NGO community kept silence due to the lack of knowledge in environmental issues and not to damage the nation's image abroad told $65 \%$ of the interviewers. The civil sector in Albania is currently going through a phase of competing together in a battle for limited resources.

NGOs often play the role of initiator in the area of sustainable development and in this way they cooperate with the local and state administration. Limited resources and capacities (human and expert) restrict these activities both in terms of time and space. That is why there is a prevalence of projects that addresses problems on a local level. 
95\% of the interviewers told that the government should treat NGOs as partners in national development, particularly in raising people's participation in the process of democratization of environment issues. The recognition of these challenges and a solution to them will impact the creation of a collective dialogue and deliberation on environmental issues that are of broad public concern.

The key of NGOs' success in the communication with the media is to get a large number of media coverage to gain social influence on policy making or to arouse public awareness told $95 \%$ of students' journalist. Though the communication strategies are helpful, it is inevitable that the environmental communicators may meet some problems when communicating with the journalists because of different perspectives and backgrounds. Thus, it be a good idea if NGOs had at least one media representative among their members who could act as an "interpreter" with the media.

The national and international aspects of sustainable development are dealt with only by a few organizations in Albania. These organizations play a crucial role in mobilizing resources for the protection of the environment and serve for the democratic social change in the country. After more than twenty years it turned out that non-profit ecological organizations had the best educational and experimental backgrounds and may also provide not only a voice to their target groups through media but they may also have a great influence on public opinions on environmental issues.

\section{Conclusions}

1. The cooperation between media and NGOs should be strengthened by organizing joint activities for raising public awareness on environmental issues.

TV programs should be organized by journalists who are specialized in the environmental field, the production of $\mathrm{CD}$ and documentary film may be developed in close cooperation with the NGOs' specialists due to their expertise.

2. Environmental education for young journalists should be instructionally sound and clear, fair and contemporary in their description of environmental problems, issues and conditions. This means that the curricula should be drafted according to the student's level and tailor-made for the specific field of study.

3. In environmental policies increasing attention must be paid to the roles of other societal actors 'education in regard to protection of the environment by making them aware of the feelings, values and attitudes that guide opinions on such issues.

4. As the field of environmental journalism covers a wide variety of topics training of the journalists and NGOs is considered as highly imperative.

5. The journalists should be able to cover both local environmental issues and global environmental concerns, and be able to deepen interdisciplinary analyses.

6. Media and environmental NGOs must strengthen their relationship and improve the cooperation during the implementation of different projects on environmental and poverty reduction issues.

\section{References}

Bernadette, M., West, L., Greenburg, R. M., Sachsman, B. D., Rogers, M. R.,(2005). The reporter's environmental handbook. 304 pp.

Bismarck, Karl von Schonhausen, Available at: http://www.worldofquotes.com/author/Karl+Otto+von+Schonhausen+Bismarck/1/index. html (July 29, 2014)

Buza, L., (2010)."Environmental education: Teaching in the Present, Preparing students for the 21st Century." Problems of Education in the 21st Century. 22., June 2010, $132 \mathrm{pp}$.

Byram. Michael., (2006). Developing intercultural awareness through language teaching and learning. Available at : http://webcache.googleusercontent.com rertrieved on July 24, 2014

Gombault \& Versteege, 1999; Frijns \& Van Vliet, 1999; Bianchi \& Noci. Role of non-governmental organizations (NGOs) in the environmental reform of small and medium-sized enterprises (SMEs) in Peru. Available at: www.sense.nl/research/(July 2, 2014)

Halverson E., \& Mcneill, C., I., (2008). Advancing a New Paradigm; Institutional and Policy Breakthroughs Toward Poverty Reduction and Sound Environmental Management. In P. Galizzi \& A. Herklotz (Eds), The Role of the Environment in Poverty Alleviation (pp 3-29). New York: Fordham University Press

Knapp, D., \& Poff, R., (2001). "A qualitative analysis of the immediate and short-term impact of an environmental interpretive program". Environmental Education Research. 7. 65pp.

Lustig, W. M., \& Koester, J., (2003). Interpersonal Communication across Cultures. Allyn \& Bacon. 336pp.

Mass-media and our environment. Available at: http://green-blog.org/archives/news/business-politics/the-mass-media-and-ourenvironment-r692 (July 29, 2014).

Ministry of Environment, Forestry and Water Administration (2008). "National Environnemental Strategy". Tirana. Albania. 168pp.

National Association of Industrial Technology (NAIT), (2009). Schools. Available at: www.miamidade.gov (May 28, 2010) 10pp.

Stone, W. C., Available at: http://thinkexist.com/quotations/environment/ (July 10, 2014). 